\title{
A Probe into the Administrative Guidance from the Perspective of Administrative Capacity: A Huai'an Story
}

\author{
Yue Zhang* \\ Department of Public Policy, City University of Hong Kong, Hong Kong
}

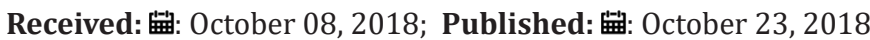

*Corresponding author: Yue ZHANG, Department of Public Policy, City University of Hong Kong, Hong Kong

\section{Background}

Huai'an is a municipality under the jurisdiction of Jiangsu province. Geographically, Huai'an covers an area of 10,072 km2 with a population of 5.4 million (till 2013) and consists of four districts (i.e., Qingjiangpu, Hongze, Huaiyin and Huai'an), and three counties (i.e., Lianshui, Jinghu and Xuyi). To implement the Outline for Law-based Administration in an all-around Way promulgated by the State Council into practice, the Administration for Industry and Commerce of Huai'an City has been conducting the administrative guidance within the whole city since 2010 .

In practice, the guiding idea for carrying out administrative guidance in Huai'an is to:

a) Actively explore new paths, new contents, new ways and new methods for the purpose of optimizing services and enhancing the quality of public service.

b) Focus on the expectations of enterprises, the competency of the authority, the demands of the corporations and the compliance with the laws to push forward the transition of the industrial and commercial administration from administrationguided to law-guided, and from management-oriented to service-oriented operation [1].

By doing so, the local government had attempted to comprehensively upgrade the industrial and commercial administration level of the city. Consequently, the promotion of the administrative guidance in the Administration for Industry and Commerce made contributions to rectify and standardize the orders of the market economy, and therefore accelerated the social and economic development. All the measures of the administration guidance concern the re-positioning of the government's functions. On the one hand, these measures have not only weakened the direct leadership and management of the local government, but also strengthened the standardization of the administrative mechanisms; on the other hand, in terms of the practical methods taken, the administrative guidance and administrative contracts have been serving as non-coercive methods.

\section{Literature Review}

In the 1960s, "Administrative Guidance" emerged in Japan, and was widely adopted in the economic and administrative management processes of many countries through the continuous development and the progress of democratization and legalization [2]. As for the connotation of administrative guidance after its localization in China, there are mainly the following explanations in the existing literature: Luo [3] pointed out that administrative guidance means that the subject of administration takes noncoercive measures in a timely and flexible manner to effectively achieve certain administrative purposes without directly producing legal effects. Luo [3] also pointed out the conditions of implementing administrative guidance: it should abide by the legal principles and policies of the state and obtain the consent or assistance of the counterparty to satisfy the complex and everchanging needs of economic and social lives. Mo [4] reckoned that administrative guidance refers to the actions such as the guidance, persuasion or advice and so forth that the administrative organ makes but without coercion and legal effects, and it is implemented by the administrative organ for certain administrative purposes.

The author believes that if the definition of the "subject of administration" is confined to administrative organs merely, it is somewhat narrowly explained. In short, administrative guidance is the non-coercive actions that an administrative organ shall carry out within the scope of its duties in order to guide the parties to act or not act for achieving certain administrative purposes. It has many characteristics including non-coercion, broad generalization, equal coordination, etc. Overall, administrative guidance shapes the soft management system together with other non-coercive 
behaviors such as administrative contract, administrative reward and administrative subsidy, all of which play active roles in the economic and social management.

\section{Issues Identified}

The industrial and commercial administration is required to broaden its original functions of the regulatory organization, market supervision and administrative law enforcement, and gradually develop its function into the cultivation of the market and the primary subjects of the market [5]. Thus, it requires that the industrial and commercial administration should shift from the traditional regulatory mode to a new flexible management mode. As such, administrative guidance, as a flexible management mode, is beneficial to making up the deficiencies of the conventional rigid management, improving the administrative efficiency, optimizing the public services, and boosting the economic development. In particular, administrative guidance, to some extent, has realized the transformation of the "therapeutic government" to the "anticipatory government" by tackling the problems and conflicts in advance instead of handling them after they occurred [1].

In addition, administrative capacity refers to the efficiency of the public sector in operating and administering its programs [6]. Another definition is that "administrative capacity refers to the ability to manage efficiently the human and physical resources required for delivering the outputs of government" [7]. In China, administrative capacity means that "in a national system, the state administrative organs reasonably establish the formal rules for universal social compliance and actively guide people through the formulation and implementation of active and effective public policies. The provisions of the administrative organs containing a wide range of well-functioning public goods and services, and they also involve the promulgation of more extensive and informal social rules to maintain the social justice and order" [8]. Practically, the administrative capacity of the government is usually associated with government functions, which directly affects the performance of the government functions. If we want to explain the administrative capacity of the government, the functions and the capacity cannot be investigated in isolation because the economic regulations, market regulations, and public services are not only the functions of the government but also the components of the government's capacity, which implies that there is an internal unity between the function and the administrative capacity of a government.

\section{The Components of the Administrative Capacity of the Industrial and Commercial Sectors}

\section{Coordination}

The capacity of coordination requires the government to make reasonable adjustments and checks to the actual conditions to facilitate economic development of a region. Thus, the basic mission of the industrial and commercial sector is to raise the living standards of the people in the region by drawing on social resources and then utilizing the resources appropriately. In addition, in the process of economic development, each subject will inevitably lead to some negative influences on the market due to the interest conflicts of various subjects, which requires that the industrial and commercial sectors should exert the positive influences and guidance on the market by making good use of its own rights [9].

\section{Supervision}

The capacity of the supervision of the industrial and commercial sectors requires the local government to promulgate policies and rules for all market transactions, to carry out supervision and inspection through the statutory procedures for specifying the standards of the market entities and the conditions for entering into the market. In addition, the supervision capacity includes regulating and supervising the service quality and investments which are directly related to the effectiveness of market competition, and integrating resources scattered in the region to build a complementary economy [9].

\section{Service Delivery}

The capacity of service delivery requires the industrial and commercial sectors not only to bring together policy information to all market players but also to instruct the development of the industry from the perspective of economic development Luo [10]. In this case, the capacity of providing services is required not only to strengthen the guidance of the industries but also to furnish the enterprises with the service of policy analysis to advance and shed light on the better and faster development of the regional economy.

\section{Administrative Law Enforcement}

The capactiy of administrative law enforcement of the industrial and commercial sectors refers to the administration under "people-centric" principles. The maintenance of a stable social order and the formulation of reasonable and legitimate solutions to tackle problems arising constitute the mission of this capacity. Consequently, the capacity of administrative law enforcement is deemed as the basis and guarantee for the other capacities of the industrial and commercial sectors and is an effective way to promote rapid economic development in the region.

\section{Solution}

\section{Optimizing and Regulating the Functions of the Industrial and Commercial Sectors}

The function of economic regulation and control is not only a substantial part of the socialist market economy but also the most crucial function of the industrial and commercial administration. It requires the industrial and commercial sectors to implement various industrial policies and promote economic development. To comprehensively perform this function, Huai'an municipal government has provided service information to the public through various means. In addition, to take the factor of fairness into account and ensure that all the citizens can share the economic achievements, the Administration for industrial and commercial of Huai'an provided counseling and guidance to some key projects, offered guidance to the small and medium-sized enterprises, and helped rural peasants and entrepreneurs return home to start up their own business. At the beginning of 2010, the Individual and Private Economic Association of Huai'an and the Administration for Industry and Commerce of Huaiyin District jointly launched a new financing approach in Huaiyin District by cooperating with the local 
Postal Savings Bank to solve the problem of narrowing financing channels for farmers in rural areas and for small and mediumsized private enterprises [11]. Jiangsu Provincial Association of Individual Economies fully praised the practice of Huai'an and demanded the promotion of such practice among individual industry and commerce households and private enterprises within the whole province.

\section{Improving the Supervision Mechanism of the Industrial and Commercial Administration}

Improving the supervision mechanism is essential for the improvement of the administrative capacity of the government. To guarantee that all the tasks included in the administrative guidance are law-based and rule-based, the Administration for Industry and Commerce of Huai'an has compiled the Administrative Guidebook and has formed five systems (e.g., the system of guidance on key projects, and the system of law violation warning). The Administration for Industry and Commerce of Huai'an has also provided eight necessary types of administrative law enforcement models used in the industrial and commercial administration, namely, administrative license, inspection supervision, advertising supervision, trademark supervision, protection of consumer rights, economic inspection, market regulation, and contract supervision. By doing so, the operational process of administrative guidance can follow its specific procedures and regulate the administrative process.

In addition, the Administration for Industry and Commerce of Huai'an has strengthened the license management through the administrative notifications of the whole process of the market. Till 2011, ten licensed management demonstration streets, nine demonstration towns and 13 demonstration markets have been set up. Despite that, in 2010, the Administration for Industry and Commerce of Huai'an has issued nearly 2000 risk warnings, which greatly declined the number of unlicensed operations and established a relevantly structured operating system for food sales industry, dangerous goods sales industry and other special industries. Through this long-term mechanism for market supervision and prevention, risks will be prevented to some extent. The strengthened management practice is recognized by all parties and it has optimized the market environment and promoted coordinated economic development.

\section{Promoting the Service Awareness to Deepen the Administrative Capacity}

Shifting from a management-oriented government to a serviceoriented government should rely on the implementation and development of new ideas, which is the basis for various wellperforming administrative functions of the government. The efforts of Huai'an to promote the administrative guidance for the industry and commerce has reinforced the business management system and extended the value of service-orientated government.

In particular, Huai'an has been vigorously promoting the "personalized service throughout the process" mechanism for the registration and management of foreign companies and increasing the degree of follow-up services for major projects to provide assistance throughout the process. As a major project, the project of Taiwan Glass Group has received the "major projects assistance" by the Administration for Industry and Commerce of Huai'an. The company's name was approved efficiently and expeditiously, and the original name of the expiring business license was retained after effective communication with the Jiangsu Provincial Administration for Industry and Commerce. In the case of the application of the Taiwanese company registration, the Administration for Industry and Commerce of Huai'an accompanied the company for entire process including sorting out materials, filling out forms, and drafting relevant documents, and also sent guidance within half a working day after it was granted by the registration management authority to complete the registration.

\section{Expanding the Approaches of Administrative Law Enforcement}

The administrative law enforcement function of the industrial and commercial administration requires the departments of the industry and commerce administration to use legal means to safeguard the normal economic order and to ensure a unified, open and competitive market system. This function is performed to standardize the market order and thus creating the conditions for further displaying the market's fundamental role in the allocation process of social resources. The Administration for Industry and Commerce of Huai'an has optimized the administrative law enforcement function by issuing a kind reminder to the administrative violations. Meanwhile, the Administration for Industry and Commerce of Huai'an also offered assistances after the administrative penalty.

In practice, for the low-degree actions and the actions without serious consequences, administrative warning or education will be used to assist to rectify their norms. In such way, the kind administration reminder, diligent administrative guidance and cautious administrative punishment have been realized. In 2010, the industrial and commercial system of Huai'an issued more than 2,000 "kind reminders of the administrative violation" in law enforcement and supervision and rectified more than 2000 minor irregularities. Thus, the efforts of guidance in law enforcement is an integration of rigidness and softness, and thus provide a guarantee to maintain a sound market order and to promote fair competition in the market. In addition, the city's commercial and industrial system has aided 307 administrative punishment from January to September 2010 which eliminated illegal activities and created a harmonious and orderly market atmosphere in Huai'an. Overall the implementation of administrative guidance has transferred the idea of law enforcement of Huai'an City, optimized the image of administration for industry and commerce, and advanced the transformation of local economic growth mode to a sound and rapid economic development.

\section{Conclusion}

The guiding idea for carrying out administrative guidance in Huai'an is to actively explore new strategies for optimizing public services and enhancing the government capacity. It should focus on the expectations of enterprises and the competency of 
the authority to push forward the transition of the industrial and commercial administration from management orientation to service orientation. In the process of carrying out administrative guidance, the Administration for Industry and Commerce of Huai'an has been adhering to the principles of legitimacy, which ensures the smooth implementation and transformation of the functions of the local government. Overall, Huai'an City has been promoting the implementation of administrative guidance work within the whole city, which complies with the trend of the enhancement of local government administrative capacity. The efforts of the local government use scientific management methods to blend the administrative guidance for industrial and commercial sectors not only embody the connotation and components of administrative capacity, but also meet the inherent requirements of the improvement of government capacity. The successful experience of administrative guidance in Huai'an deserves broader promotion among the industrial and commercial of other cities.

\section{References}

1. Administration for Industry and Commerce of Huai'an (2009). Huai'an Administration for Industry and Commerce Administrative Guidebook.

2. Narita Y (1968) Administrative Guidance. Law Japan 2: 45.

3. Luo Haocai (1996) Administrative Law, Peking University Press.
ISSN: 2574-1241

DOI: $10.26717 / B J S T R .2018 .10 .001923$

Yue ZHANG. Biomed J Sci \& Tech Res

This work is licensed under Creative Commons Attribution 4.0 License

Submission Link: https://biomedres.us/submit-manuscript.php
4. Mo Yuchuan (2004) Administrative Guidance in the Perspective of Law A Debate on the Legitimacy of Administrative Guidance and the Route of Legalization in China. Modern Law 26(3): 3-13.

5. Chen Jixiu (2009) Analysis of Functions of Industrial and Commercial Administration, Chinese Public Administration 1: 019.

6. Edwards L (2009) Testing the discourse of declining policy capacity: Rail policy and the Department of Transport. Australian Journal of Public Administration 68(3): 288-302.

7. Tao J, Mah DNY (2009) Between market and state: dilemmas of environmental governance in China's sulphur dioxide emission trading system. Environment and Planning C: Government and Policy 27(1): 175-188.

8. Zhang Guoqing (2000) Introduction to Administration. Peking University Press, Beijing, China.

9. Wang Yongcheng (2001) Governmental Capacity in the Process of China's Modernization - Status and Prospects of Research on Governmental Capacity in Domestic Academia, Studies in Political Science 4: 79-88.

10. Luo Chongpu (2008) The "Third Road" Theory and Participatory Governance Model Building Strategy. Sichuan Provincial Committee of the Communist Party of China.

11. Administration for Industry and Commerce of Huai'an (2010). Huai'an Industrial and Commercial System Administrative Guidance - The Compilation of Demonstration Projects.

$\begin{array}{ll}\text { BIOMEDICAL } & \text { Assets of Publishing with us } \\ \text { RESEARCHES } & \text { Global archiving of articles } \\ \text { - Immediate, unrestricted online access }\end{array}$

